\title{
Validating the Use of Slag Binder with 91 Percent Blast Furnace Slag for Mine Backfilling
}

\author{
Xiaobing Yang, Bolin Xiao $\mathbb{D}$, and Qian Gao \\ School of Civil and Resource Engineering, University of Science and Technology, Beijing, China \\ Correspondence should be addressed to Bolin Xiao; iextia@hotmail.com
}

Received 14 July 2020; Revised 11 September 2020; Accepted 18 September 2020; Published 30 September 2020

Academic Editor: Erol Yilmaz

Copyright (c) 2020 Xiaobing Yang et al. This is an open access article distributed under the Creative Commons Attribution License, which permits unrestricted use, distribution, and reproduction in any medium, provided the original work is properly cited.

\begin{abstract}
The use of ground granulated blast furnace slag (GGBFS) is environmentally sustainable and prevalent in the cement industry, but the original alkali-activated slag binder cannot be used for mine backfilling. Few reports have studied slag binders with high slag proportions ( $>90 \%)$ and low-cost activators (solid waste is used) that have higher performance than cement for backfilling. To increase the utilization of slag in the mining industry, this work presents a new slag binder (SB) comprised of $91 \%$ slag powder and 9\% activator (3\% clinker, $5 \%$ desulfurized gypsum, and 1\% mirabilite). Its performance was evaluated by testing its strength, yield stress, and viscosity, which are three key properties for backfilling. We also investigated its microstructure using SEM, XRD and thermogravimetric analysis (TG/DTG). The results showed that the SB composites have a slightly lower early-age $(<3 \mathrm{~d})$ strength but a higher long-term strength ( $>28 \mathrm{~d}$ ). Although the SB backfilling composites had a twofold higher yield stress and nearly the same viscosity as Portland cement, the pressure drop in a pipe was only slightly higher through friction factor modeling. The proposed SB may provide a sustainable binder for the mining industry with better performance and lower cost.
\end{abstract}

\section{Introduction}

The metallurgical and mining industries produce large quantities of by-products and solid wastes such as slag, waste rock, and tailings, which are generally disposed of in landfills, which raises environmental issues. Blast furnace slag is generated during iron manufacturing, and $95 \%$ of it is comprised of four main oxides: calcium, magnesium, silicon, and aluminum [1]. Blast furnace slag has been used for centuries in many fields. For example, some of the firstknown uses of blast furnace slag were as railroad ballast, as a concrete aggregate, in bituminous surfaces, asphalt mixtures, pavement structures, unbound base courses, and embankments [2-6]. Slag is most commonly used in the cement industry due to the similar chemical compositions of the two materials. It is ground to a cement-like grain size known as grounded granulated blast furnace slag (GGBFS) and then used as a cement additive and independent binder $[7,8]$.

A traditional cement raw material is clinker, whose production is accompanied by large quantities of greenhouse gas emissions, dust air pollution, and excavated clay soil for calcination. The replacement of GGBFS with clinker can address these issues. An academic report found that replacing $45 \%$ of ordinary Portland cement with blast furnace slag would result in a $37 \%$ reduction in total $\mathrm{CO}_{2}$ emissions [9]. The use of a higher slag proportion in cement can decrease the total energy required for cement manufacturing [10]. Important applications of alkali-activated slag binder and slag composite binder used in mortar and construction concrete have been reported [11-14]; however, these binders may not be applicable for mine backfilling, which is vastly different from ordinary concrete.

Mine backfill slurries are mixtures of binder, aggregate, and water that are homogeneously mixed in a surface plant and then transported to fill underground voids by gravity or pumping through pipelines [15]. Compared with normal concrete, mine backfill has special characteristics such as follows: (i) low binder content $B_{w} \%$ (mass percentage of binder/solid mass), which is determined by the geological conditions of the mine and the functionality of the filling body. It usually ranges from 2 to $8 \%$ [16], but in most mines 
in China, $10-20 \%$ is used due to complex geological conditions, such as high in situ stresses and crushed wall rock. In ordinary concrete, $B_{w} \%$ is more than $30 \%$. (ii) High water/ cement ratio $(W / C)$. The $W / C$ is $<1.0$ for construction concretes, while mine backfill has a larger $W / C$ of $2-10$ to improve flow through pipeline transport [17]. (iii) Backfill aggregate can be composed of many different materials, such as tailings, waste rock, solid waste, river sand, and Gobi sand. Aggregate also has a large content of fine particles $(<75 \mu \mathrm{m})$; for example, fine particles may account for more than $80 \%$ of tailings [18]. Construction concrete generally has a rigid fine particle content limit of $<5 \%$. The strength of concrete significantly decreases upon increasing the fine particle content [19]. (iv) Tap water may be used for mixing mine backfill, but processed water rich with chloride ions, metal ions, sulfate ions, and many other chemicals are generally used. These ions can have complex effects on hydration reactions [20].

With these unique characteristics, the slag binders originally developed for building and civil construction may no longer be suitable for mine backfill. Binders are often specially developed and should be validated for use at mine sites. For example, Olivier used four pozzolanic by-products (waste glass, copper slag, wood bottom ash, and coal fly ash) mixed with Portland cement and GGBFS to create low-cost binders for use in mine cemented paste backfill [21]. The cement replacement level of 35\%-45\% was validated. Jiang developed an alkali-activated slag with an activator/slag ratio of 0.3 (slag proportion 77\%), and the paste backfill workability and early-age compressive strength were confirmed [22].

However, there are few reports of slag binder with large slag proportions (>90\%) and low-cost activators (solid waste) with a higher performance than cement for mine backfill. In this study, a new slag binder made of $91 \%$ slag and $9 \%$ activator is presented and examined for mine backfill. Validation tests were performed on the strength and rheological properties (yield stress and viscosity), which are three key properties for backfill. We also investigated the microstructure using SEM, XRD, and thermogravimetric analysis (TG/DTG) to compare the material with ordinary Portland cement type I (PCI) and PCI-slag blended binder to evaluate its performance.

\section{Materials and Methods}

\subsection{Materials}

2.1.1. Binder Materials. Three kinds of binders were used: PCI (CB, which is used industrially), 50/50 PCI-slag blinded binder $(\mathrm{BB}$, which is widely used in many other mines and literature), and the proposed slag binder (SB). The slag was obtained from JISCO in Gansu Province, China, and ground into GGBFS in a local plant. Many studies have reported that the hydration of GGBFS can be activated by alkali [23] and sulfate [24]. Here, a combination activation was applied, in which a small amount of clinker was used to generate an alkali environment, desulfurized gypsum (a solid waste byproduct of thermal power plants or iron-steel plants) was used as a sustainable sulfate activator, and a very small amount of mirabilite was added to improve the early strength. The SB consisted of 91\% GGBFS, 3\% clinker, 5\% desulfurized gypsum, and $1 \%$ mirabilite. The main physical and chemical properties of PCI and GGBFS are listed in Table 1 . GGBFS is an acidic slag $\left(M_{0}<1\right)$, and the quality coefficient $K>1.2$ indicates that it has a good hydration property.

2.1.2. Aggregate. To validate the applicability of the SB for mine backfilling, a practical high-density backfill (HDB) slurry of a nickel mine in northwest China was used. A Gobi sand aggregate was obtained from the mining site, which was excavated from the Gobi, and then sieved and milled in a processing plant to eliminate extra-coarse particles and ensure that the maximum grain size was $<5 \mathrm{~mm}$. The final grain size distribution of Gobi sand is shown in Figure 1, which has a fine particle $(<75 \mu \mathrm{m})$ content of $16.5 \%$.

2.1.3. Mixing Water. Tap water was used as the mixing water to simulate an actual engineering situation. Although water chemistry can affect some properties of the backfill slurry [25], this is beyond the scope of this research, which focuses on strength and rheological properties.

\subsection{Test Methods}

2.2.1. Uniaxial Compression Strength (UCS) Tests. The UCS is an important parameter for mine backfilling, because it determines the functionality of the filling mass body, the backfill slurry configuration, the backfilling cost, and mining profitability; therefore, it was used to evaluate the binders in this research. UCS tests were performed on specimens with three different binders for different curing times $(1,3,7$, and $28 \mathrm{~d}$ ) in accordance with the ASTM C109 standard. A microprocessor-controlled electronic universal testing machine LGS100 K model was used with a loading capacity of $100 \mathrm{kN}$ and an accuracy of $0.5 \%$. The loading rate was $1 \mathrm{~mm} /$ min during the tests. Before the tests, a high-density backfill (HDB) mixture was prepared using the practical mixing proportion of binder content of $B_{w} \%=20 \%$ and a solid mass concentration of $C_{w} \%=78 \%$. The binder, aggregate, and water were mixed in a mixing machine for 5 minutes and then poured into a cube triple-module with a side length of $7.07 \mathrm{~cm}$. The module was sealed by a plastic wrap to prevent water evaporation and then placed into a temperaturecontrolled chamber at $23^{\circ} \mathrm{C}$ for the designated curing time.

The test for each specimen was repeated at least three times to ensure accuracy and repeatability, and the average value was reported as the strength of the tested sample.

2.2.2. Rheology Tests. Rheology is another important feature for mine backfilling, since the slurry is transported by pipeline, and the slurry flow in a pipe is dominated by its rheological properties. Thus, it is essential to evaluate the rheological properties when applying a backfill material, which is generally characterized by its yield stress and 
TABLe 1: Chemical and physical properties of PCI and GGBFS.

\begin{tabular}{|c|c|c|c|c|c|}
\hline Chemical composition & PCI (\%) & GGBFS (\%) & Physical properties & PCI & GGBFS \\
\hline $\mathrm{CaO}$ & 62.82 & 37.95 & Specific gravity & 3.1 & 2.9 \\
\hline $\mathrm{Fe}_{2} \mathrm{O}_{3}$ & 2.7 & 0.63 & Specific surface area $\left(\mathrm{m}^{2} / \mathrm{kg}\right)$ & 430 & 460 \\
\hline $\mathrm{SiO}_{2}$ & 18.03 & 38.34 & Fines content $(<45 \mu \mathrm{m})(\%)$ & 88 & 95 \\
\hline $\mathrm{Al}_{2} \mathrm{O}_{3}$ & 4.53 & 12.3 & Basicity coefficient, $M_{\mathrm{o}}$ & - & 0.90 \\
\hline $\mathrm{MgO}$ & 2.65 & 7.82 & Quality coefficient, $K$ & - & 1.50 \\
\hline $\mathrm{MnO}$ & 0.41 & 0.48 & $D_{10}(\mu \mathrm{m})$ & 2.85 & 4.48 \\
\hline $\mathrm{K}_{2} \mathrm{O}$ & 0.73 & 0.52 & $D_{50}(\mu \mathrm{m})$ & 17.04 & 12.13 \\
\hline $\mathrm{SO}_{3}$ & 3.82 & 0.2 & $D_{90}(\mu \mathrm{m})$ & 43.67 & 61.68 \\
\hline
\end{tabular}

Note: $\mathrm{Mo}=(\mathrm{CaO}+\mathrm{MgO}) /\left(\mathrm{Al}_{2} \mathrm{O}_{3}+\mathrm{SiO}_{2}\right) ; \mathrm{K}=\left(\mathrm{CaO}+\mathrm{MgO}+\mathrm{Al}_{2} \mathrm{O}_{3}\right) /\left(\mathrm{SiO}_{2}+\mathrm{MnO}+\mathrm{Ti}_{2} \mathrm{O}\right)$.

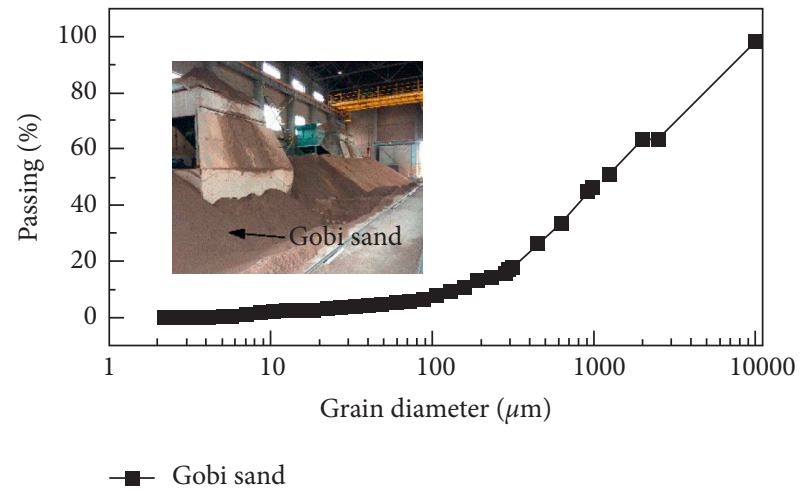

FIGURE 1: Grain size distribution of Gobi sand.

viscosity; therefore, rheology tests were performed using a Brookfield RST Soft Solids Tester (RST-SST) Rheometer and a Rheo3000 software for the HDB with different binders. The tests were conducted at room temperature using a four-blade vane spindle VT-40-20. The rheometer was set to controlled shear rate (CSR) mode, and HDB samples were sheared at a shear rate range of $0-200 \mathrm{~s}^{-1}$. Before the tests, all materials were homogeneously mixed in a mixing machine for $5 \mathrm{~min}$, and then the sample was placed in a $600 \mathrm{~mL}$ low-form Griffin beaker for measurement. During the test, samples were first sheared at a maximum rate $\left(200 \mathrm{~s}^{-1}\right)$ for $2 \mathrm{~min}$ to simulate the shear that occurs in practice during mixing before slurries are directly dumped into a pipeline system without silencing. Then, the sample was sheared from a rate of $200 \mathrm{~s}^{-1}$ declining to $0 \mathrm{~s}^{-1}$ over $100 \mathrm{~s}$, with data recorded every $10 \mathrm{~s}$.

2.2.3. Microstructural Analysis. Microstructural analysis, including thermal analyses (thermogravimetry (TG), differential thermogravimetry (DTG)), scanning electron microscope (SEM), and X-ray diffractometry (XRD), were carried out to inspect the HDB properties. TG/DTG and $\mathrm{XRD}$ were conducted on the three binder paste samples, which were a mixture of binder and water with a $W / C$ ratio of 1 . The SEM samples were made from the cracked cube after UCS tests. To prepare paste samples, the binders and water were mixed using the same procedure and then sealed in a chamber for the desired curing time. Prior to tests, samples were dried in an oven at $40^{\circ} \mathrm{C}$ until mass stabilization and then ground into powders for measurement.
Thermal analyses were carried out using an SDT-Q600 TGA from TA Instruments, which allowed the simultaneous measurement of weight loss, heat flow, and transition temperature changes. The paste samples (about $10 \mathrm{mg}$ ) were heated in an inert nitrogen atmosphere at a rate of $10^{\circ} \mathrm{C} / \mathrm{min}$ up to $800^{\circ} \mathrm{C}$ during tests.

XRD was conducted to acquire the mineralogical and chemical compositions of the HDB. It was performed using a Bruker D8 advance diffractometer. The scanning was carried out over a $2 \theta$ range of $5-70^{\circ}$ with a step width of $0.02^{\circ}$ and a scanning speed of $1^{\circ} / \mathrm{min}$.

SEM observations were performed with a JEOL JSM$6700 \mathrm{~F}$, operating in a backscatter electron mode.

\section{Results and Discussion}

UCS and rheological properties were examined to validate the applicability of sustainable slag binder as mine backfill.

3.1. Strength (UCS) Development of the HDB with Different Binder Agents. The UCS developments of the HDB samples with three binder agents (CB-HDB, BB-HDB, and SB-HDB) are shown in Figure 2.

It can be seen that the BB-HDB has the lowest strength for all times, $\mathrm{HDB}$ with a blended binder, and slag binder has nearly the same minimum strength after curing for $1 \mathrm{~d}$ and $3 \mathrm{~d}$. Although HDB with PCI binder has the highest early strength $(<7 \mathrm{~d})$, the SB-HDB shows the highest strength at $7 \mathrm{~d}$ and $28 \mathrm{~d}$. PCI binder has the highest early strength, and partial replacement with slag reduced the UCS. The developed slag binder has a better performance for midterm $(7 \mathrm{~d})$ and long-term strength $(28 \mathrm{~d})$.

3.1.1. Early-Age Strength (Curing $\leq 3 d$ ) and Hydration Products. BB-HDB has the lowest strength at $1 \mathrm{~d}$ and $3 \mathrm{~d}$ of $0.41 \mathrm{MPa}$ and 1.23 MPa. SB-HDB has a slightly higher $3 \mathrm{~d}$ strength of $1.33 \mathrm{MPa}$, while CB-HDB has the highest $1 \mathrm{~d}$ and $3 \mathrm{~d}$ strength of $0.77 \mathrm{MPa}$ and $1.97 \mathrm{MPa}$, respectively. The highest strength for $\mathrm{CB}-\mathrm{HDB}$ was attributed to the rapid hydration rate of its main components $\left(\mathrm{C}_{3} \mathrm{~A}, \mathrm{C}_{3} \mathrm{~S}\right.$, and $\mathrm{C}_{4} \mathrm{AF}$ ). The hydration process begins immediately when water is added to produce hydration products, such as hydrated calcium silicate $(\mathrm{C}-\mathrm{S}-\mathrm{H})$, calcium hydroxide $(\mathrm{CH})$, and ettringite (AFt) [26]. In contrast, slag has a slow hydration rate, and slag particles are only hydrated after an 


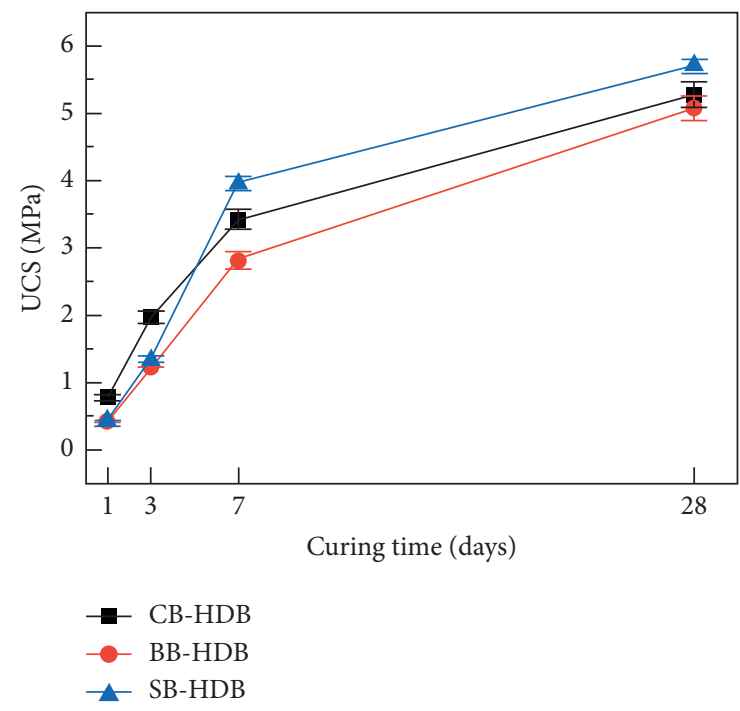

Figure 2: UCS developments for CB-HDB, BB-HDB, and SBHDB.

alkali activator reacts with water to produce $\mathrm{CH}$ [27]. The active ingredients of the slag create a silicic-rich gel, which then reacts with $\mathrm{CH}$ to produce C-S-H gel. Furthermore, slag can react with sulfate activator (gypsum) to generate ettringite [28]; however, gypsum has a very low solubility in water, which means this hydration process will last for a long time. SEM images were collected to inspect the microstructures of CB-HDB and SB-HDB, as shown in Figure 3.

As illustrated in Figure 3, the main hydration products, such as C-S-H (clusters) and ettringite (bars), were observed in both samples after curing for $3 \mathrm{~d}$. CB-HDB was more developed with denser and bigger $\mathrm{C}-\mathrm{S}-\mathrm{H}$ and ettringite clusters, while SB-HDB was less developed with many unfilled voids. Consequently, SB-HDB has lower early-age strength due to the presence of more voids and less-developed hydration products. A TG/DTG analysis of binder paste was conducted for validation, as shown in Figure 4.

Figure 4 shows that there are three DTG peaks or weight loss for both binder pastes. The first weight loss occurs around $100^{\circ} \mathrm{C}$, which is a result of the dehydration reactions of some hydrates such as $\mathrm{C}-\mathrm{S}-\mathrm{H}$, carboaluminates, ettringite, and gypsum [29]. The second weight loss occurs near $400^{\circ} \mathrm{C}$, which is caused by the dehydroxylation of calcium hydroxide [30]. Finally, a third peak is observed near $700^{\circ} \mathrm{C}$, which is attributed to the decomposition of calcite [31]. Overall, the total weight loss for the CB paste $(21.5 \%)$ is larger than that of SB (14.5\%) after curing for 3 days, which demonstrates that the amount of hydration products for $\mathrm{CB}$ is larger. Although the third peak of SB is considerably lower, which indicates a lower hydration rate, the first peak for SB is higher, which indicates that SB has a greater amount of C-S$\mathrm{H}$ after curing for 3 days due to the reaction of slag with $\mathrm{CH}$. The extra consumption of $\mathrm{CH}$ implies a lower second peak for SB, even though the second peak for both binders is relatively low.
3.1.2. Midterm (7d) and Long-Term Strength (28d). The UCS of backfill cured for 28 days is mainly controlled by the binder content $B_{w} \%$. It is a crucial parameter for mine design, because it determines the mixing proportion and, thus the backfill cost. In this case, the $28 \mathrm{~d}$ UCS of the ordinary $\mathrm{CB}-\mathrm{HDB}$ is $5.27 \mathrm{MPa}$, which is 1.05 times higher than the design requirement (here, a minimum of $5 \mathrm{MPa}$ is required for ground support at $28 \mathrm{~d}$ curing, which is determined in the strength design process due to the extremely high in situ stress load, underhand cut-and-fill mining method requirement, and large portion of coarse Gobi sand used as aggregate). The UCS of BB-HDB is $5.08 \mathrm{MPa}$ which is $96.4 \%$ of CB-HDB, but the UCS for SB-HDB reached $5.69 \mathrm{MPa}$ which is 1.14 times higher than the requirement. This result implies that the combination activation SB has a higher performance than SB during long-term curing, which is beneficial for mining in both mechanical properties and cost. The higher long-term performance is attributed to the second hydration process of slag with alkali and sulfate. This produces complex products, such as ettringite (AFt), gypsum, C-S-H, hydrocalumite, and dolomite. The XRD patterns of the three binder pastes after curing for $28 \mathrm{~d}$ are presented in Figure 5 to illustrate the difference in hydration products.

It can be seen that SB produces more complex hydration products, but Portlandite $(\mathrm{CH})$ is absent because (i) SB only contains $3 \mathrm{wt} \%$ clinker, which generates only a small amount of $\mathrm{CH}$; (ii) the $91 \mathrm{wt} \%$ GGBFS in SB can react with $\mathrm{CH}$ to generate extra C-S-H gel. Therefore, $\mathrm{CH}$ in the $\mathrm{SB}$ is completely consumed and absent in Figure 5. Reports have shown that $\mathrm{CH}$ does not improve the strength, but it is harmful to the interface transition zone (ITZ), which reduced the strength [32]. In sum, the absence of $\mathrm{CH}$ and the extra C-S-H contribute to the higher mechanical performance of the SB. More AFt and dolomite $\left(\mathrm{CaCO}_{3}\right)$ were detected for the SB due to its complex hydration reaction. Higher mechanical performance is typical of more extrusive paste backfill with ultrafine tailings [33-35]. The cost of SB comprised of $91 \%$ GGBFS which can vary geographically, but in China, it is generally $100 \mathrm{CNY} /$ ton cheaper than ordinary Portland cement. Besides, the binder has more environmental benefits, such as lower greenhouse gas emissions, use of natural raw materials during cement production, and iron and steel industry sustainable development.

3.2. Rheological Properties of the HDB. The rheological properties of the HDB with different binder agents were evaluated and compared. Similar to most reported materials, the HDB slurry exhibited Bingham plastic flow, as shown in Figure 6. Although there are some unusual points in Figure 6, which are supposed to be caused by the collision of rotational vane spindle (length $40 \mathrm{~mm}$ and diameter $20 \mathrm{~mm}$ ) and large aggregate particles (maximum diameter $5 \mathrm{~mm}$ ), the Bingham model fitting shows a reasonable result with an adjusted $R^{2}>0.9$. 


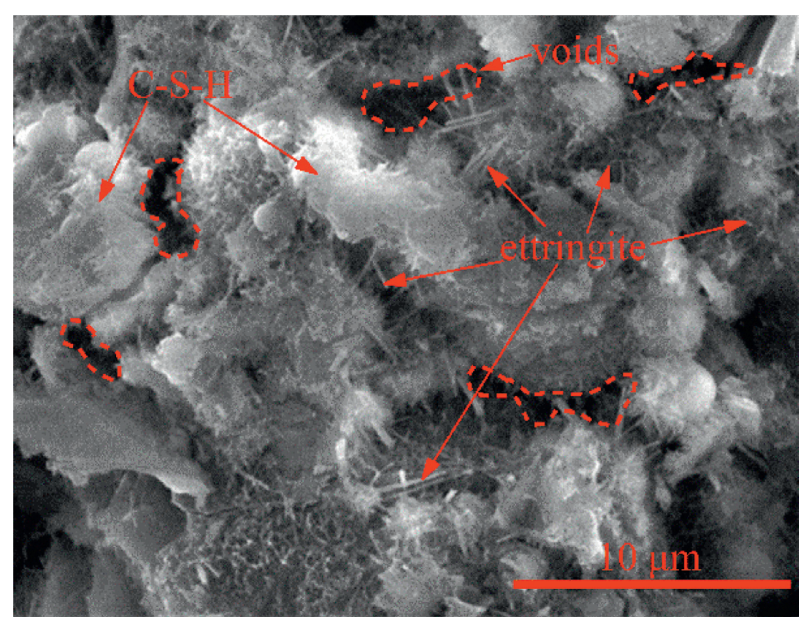

(a)

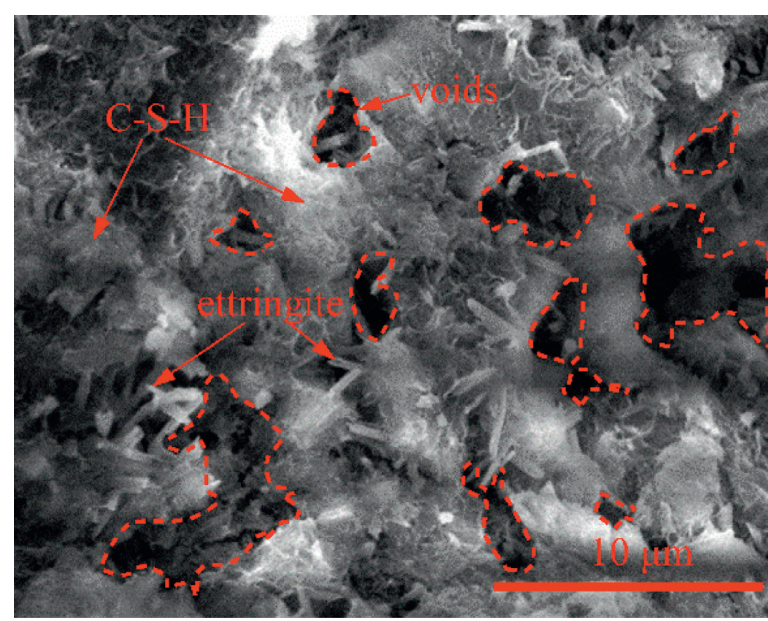

(b)

Figure 3: Microstructures (SEM) of (a) CB-HDB and (b) SB-HDB after curing for 3 days.

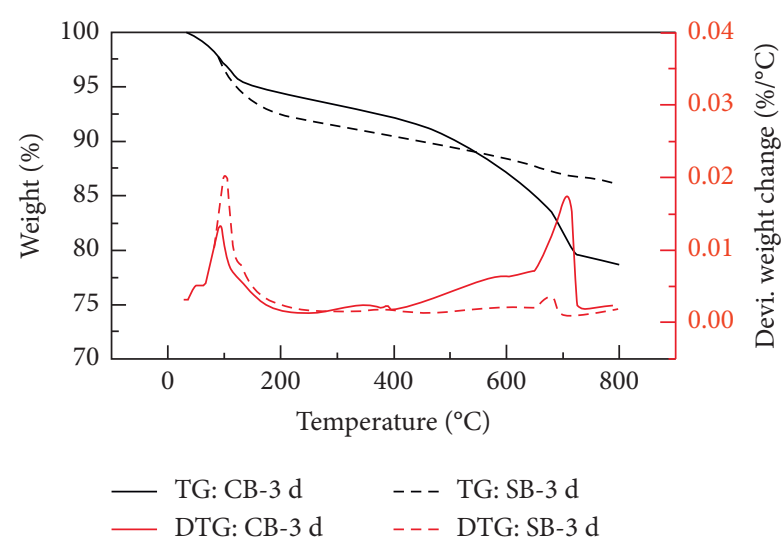

Figure 4: TG/DTG analysis for CB and SB paste after curing for 3 days.

3.2.1. Yield Stress. From Figure 6, the practical use of CBHDB had the lowest dynamic yield stress of $5.90 \mathrm{~Pa}$, which fully meets the requirement for gravity transport. The yield stress increased to $7.1 \mathrm{~Pa}$ when half of PCI was replaced by GGBFS in BB-HDB, and it nearly doubled to $11.50 \mathrm{~Pa}$ for SB-HDB when $91 \%$ GGBFS was used. This finding indicates that the backfill slurry with GGBFS has a higher yield stress than without GGBFS, which can be explained by the following two mechanisms: (i) GGBFS has a larger specific surface area and fine particle content than PCI; therefore, the formed cementitious gel has a larger surface area when mixed with water, which will, in turn, capture more free water molecules. Thus, the distance between solid particles is reduced, and flocculation and interparticle attractive forces are enhanced, which increases the minimum external force required to break the microstructure (yield stress) and induce flow; (ii) GGBFS can improve the grain size distribution of the mixtures because of its finer particle size $\left(d_{50}=12.13 \mu \mathrm{m}\right.$. This allows the tiny pores between aggregate particles to be filled, which reduces the porosity and produces more compact mixtures with a higher packing density, which increases the yield stress.
This finding is consistent with many other studies in the literature. References $[36,37]$ found that the slag grains with more edges produced high shear stresses, and a higher slag percentage produced higher normal shear stresses.

3.2.2. Viscosity. Figure 6 also shows that the viscosity only slightly changed, regardless of the binder agent. They are $0.431 \mathrm{~Pa} / \mathrm{s}, 0.455 \mathrm{~Pa} / \mathrm{s}$, and $0.446 \mathrm{~Pa} / \mathrm{s}$ for CB-HDB, BB-HDB, and SB-HDB respectively. The apparent viscosities were nearly the same as the three HDB during the test, as shown in Figure 7. It can be observed that the apparent viscosity completely overlapped for the three $\mathrm{HDB}$ and remained constant at $0.4 \mathrm{~Pa} / \mathrm{s}$ when the shear rate exceeds $50 \mathrm{~s}^{-1}$. It can be concluded that the binder type does not affect the viscosity in this case.

3.2.3. Discussion on Rheological Properties. From the above results, the binder agent only slightly changed the yield stress but had nearly no effect on the viscosity for the HDS; however, it is difficult to determine how large of a change of the viscosity will be significant. The magnitude of the rheological property changes is far from practical use when expressed in terms of yield stress and viscosity. Another widely used practical parameter is the pressure drop or friction factor, which evaluates the pressure loss of the backfill slurry when transported via pipeline. The friction factor is closely related to the yield stress, viscosity, and engineering conditions, such as the pipe diameter, flow state (laminar, turbulent, and transition flow), flow rate (velocity), Reynolds number, and slurry bulk density. Many models can be used to predict the friction factor with high accuracy $[38,39]$. To better evaluate the practical applicability of the $\mathrm{SB}$, the pressure drop of the three HDBs will be calculated and compared using a friction factor correlation.

Before selecting the model, the flow state of the HDB under practical conditions should be determined, which is evaluated by the Reynolds number $\mathrm{Re}$ as shown in equation (1): 


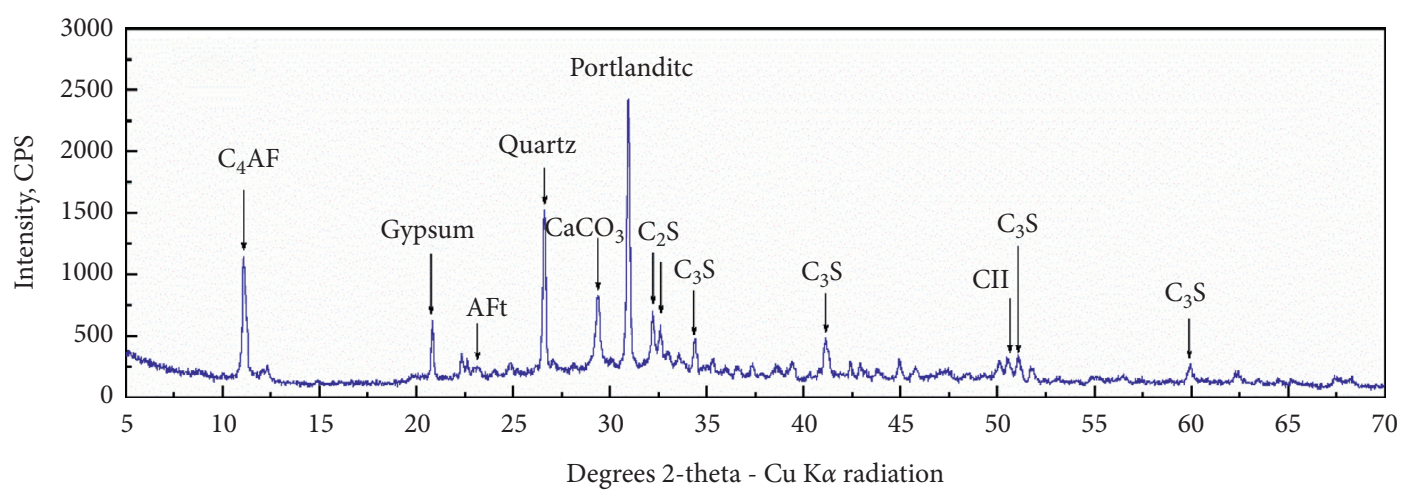

(a)

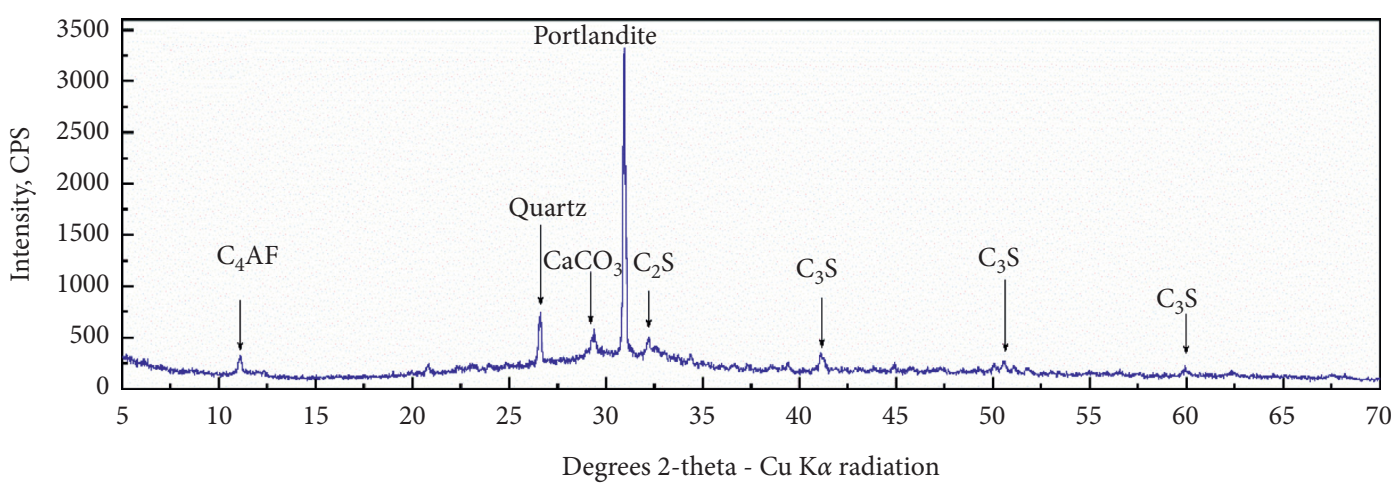

(b)

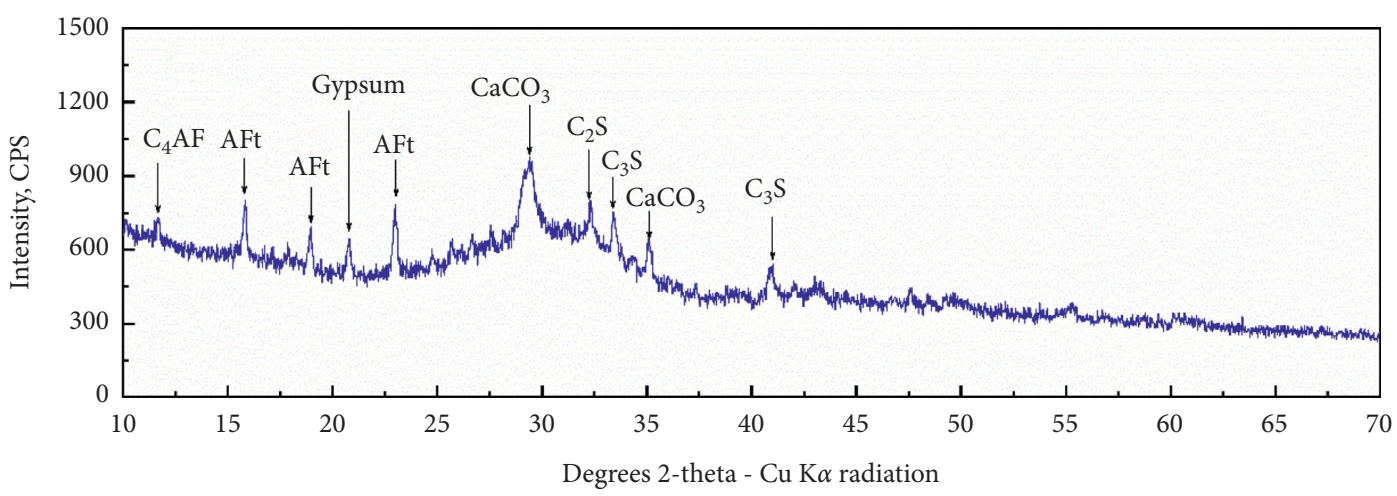

(c)

Figure 5: XRD patterns for (a) CB, (b) BB, and (c) SB pastes after curing for 28 days.

$$
\operatorname{Re}=\frac{\rho v D}{\mu_{p}}
$$

where $\rho$ is the slurry bulk density, $\mathrm{kg} / \mathrm{m}^{3} ; v$ is the flow velocity, $\mathrm{m} / \mathrm{s} ; D$ is the pipe diameter, $m$; and $\mu_{p}$ is the plastic viscosity of a Bingham plastic fluid, $\mathrm{Pa} / \mathrm{s}$.

In this case, the pipe diameter was $110 \mathrm{~mm}$, the flow velocity in the pipe ranged from $2.0 \mathrm{~m} / \mathrm{s}$ to $3.0 \mathrm{~m} / \mathrm{s}$, the bulk densities of the BB-HDB, CB-HDB, and SB-HDB were $1740.5,1744.8$, and $1736.08 \mathrm{~kg} / \mathrm{m}^{3}$, respectively, and the plastic viscosities are shown in Figure 8 . The calculated $\mathrm{Re}$ ranged from 840 to 1336 , which falls in the laminar flow regime $(\operatorname{Re}<2100)$. Furthermore, HDB behaves as a Bingham plastic fluid as shown earlier; consequently, the
Buckingham-Reiner friction factor correlation [39] was used to calculate the friction factor, as shown in equation (2):

$$
f=\frac{64}{\operatorname{Re}}\left[1+\frac{1}{6} \frac{\mathrm{He}}{\operatorname{Re}}-\frac{64}{\operatorname{Re}}\left(\frac{\mathrm{He}^{4}}{f^{3} \mathrm{Re}^{7}}\right)\right],
$$

where $f$ is the friction factor; He is the Hedstrom number and $\mathrm{He}=\left(\left(\rho D^{2} \tau_{B}\right) / \mu_{p}^{2}\right)$; and $\tau_{\mathrm{B}}$ is the yield stress of a Bingham plastic fluid.

Once the friction factor is determined, the friction head loss can be determined by the Darcy-Weisbach equation [28] using the following equation:

$$
f=\frac{2 h_{\mathrm{f}} g D}{L v^{2}}
$$




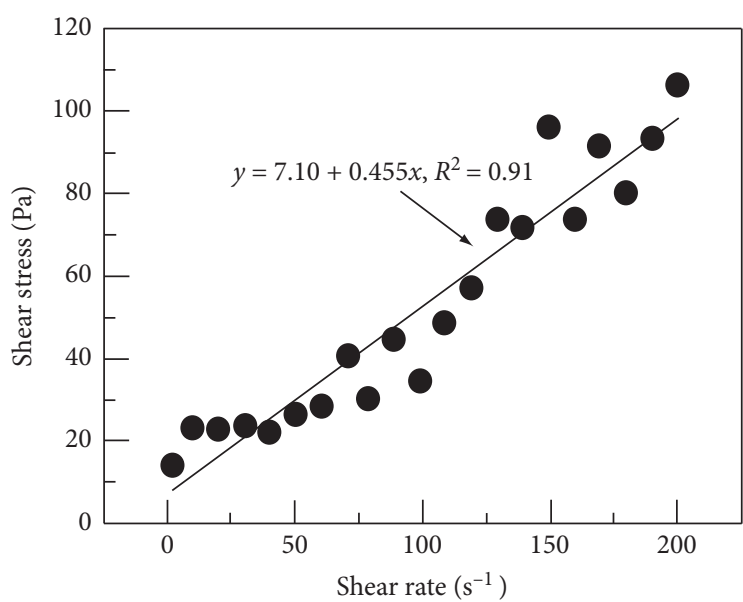

BB-HDB

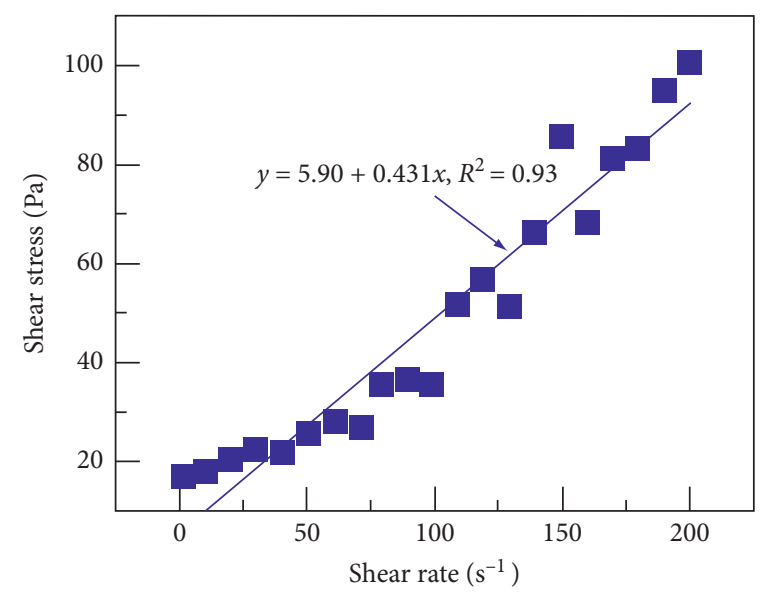

CB-HDB

(a)

(b)

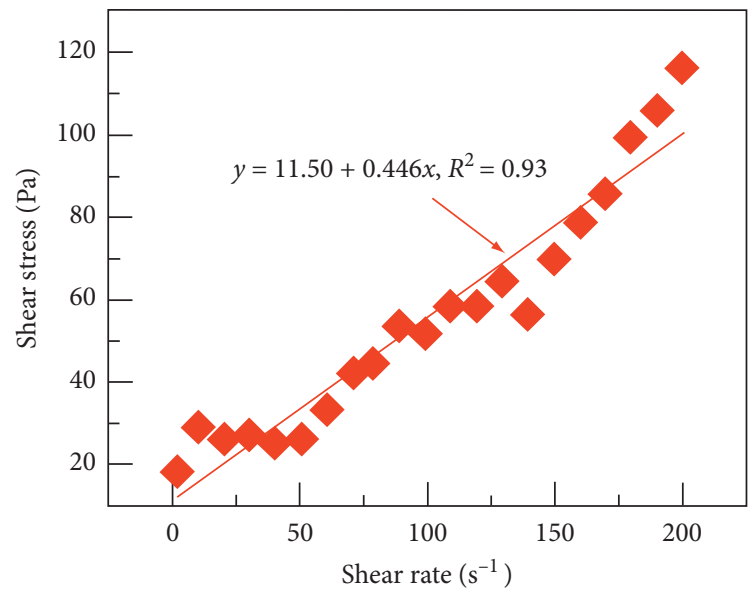

SB-HDB

(c)

Figure 6: Rheological properties (shear rate vs. shear stress) of (a) BB-HDB, (b) CB-HDB, and (c) SB-HDB.

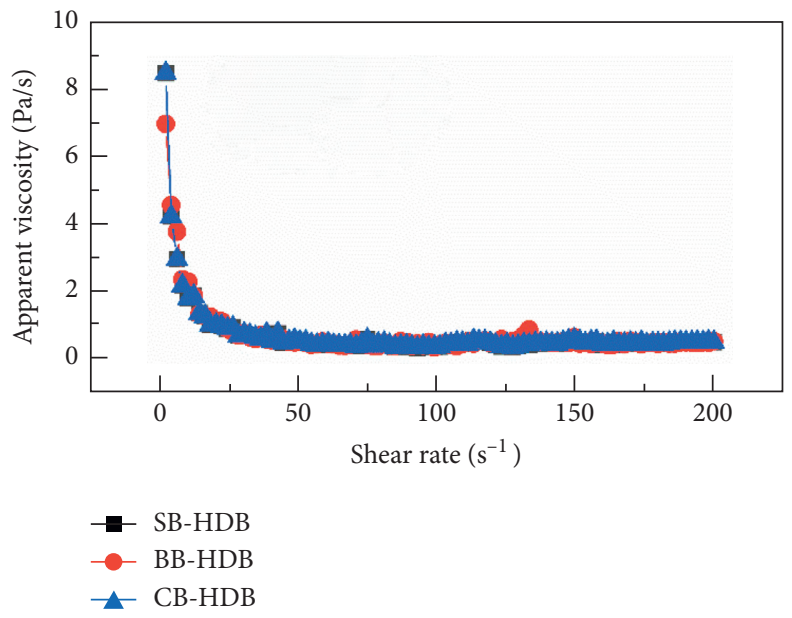

Figure 7: Apparent viscosity for SB-HDB, BB-HDB, and CB-HDB. 


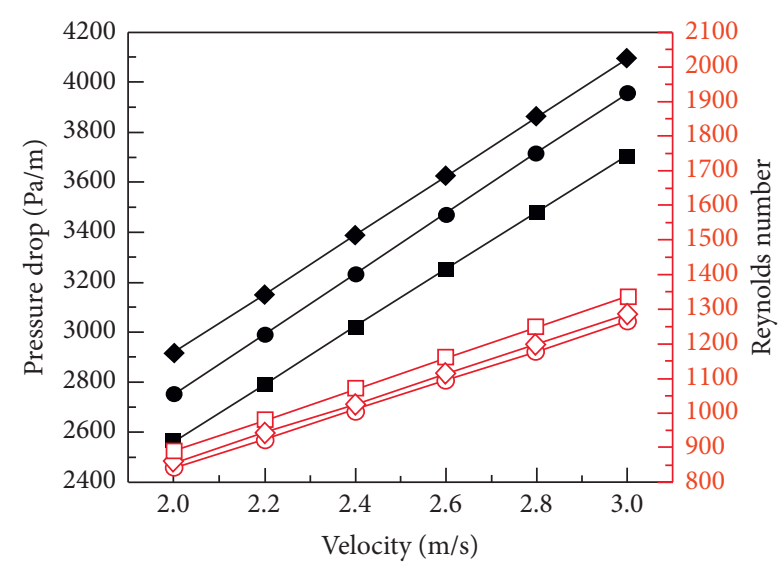

$$
\begin{array}{ll}
\text { Pressure drop } & \text { Reynolds number } \\
\rightarrow \text { BB-HDB } & - \text { - BB-HDB } \\
\rightarrow \text { CB-HDB } & -\square \text { CB-HDB } \\
\bullet \text { SB-HDB } & -\checkmark \text { SB-HDB }
\end{array}
$$

FIGURE 8: Calculated pressure drop and Reynold's number for SB$\mathrm{HDB}, \mathrm{BB}-\mathrm{HDB}$, and CB-HDB.

where $h_{\mathrm{f}}$ is the friction head loss, $g$ is the acceleration of gravity $\left(\mathrm{m} / \mathrm{s}^{2}\right)$, and $L$ is the length of the pipeline $(m)$.

Finally, the friction head loss can be converted to a pressure drop $i_{m}$ according to the following equation:

$$
i_{m}=\frac{\rho g h_{\mathrm{f}}}{L}=\frac{\rho f v^{2}}{2 D} .
$$

According to the described procedure, the calculated pressure drops for the three HDB are shown in Figure 8. PCI has the lowest pressure drop, while the slag binder with $91 \%$ GGBFS has a slightly higher pressure drop than HDB (approximately $350 \mathrm{~Pa} / \mathrm{m}$ ), even with the doubled yield stress and a small increase in viscosity mentioned earlier. In other words, the flowability of the SB-HDB was not much different than that of PCI.

\section{Conclusions}

This work reported a slag binder for mine backfilling with a large slag proportion (>90\%), low-cost activator (solid waste), and higher performance than cement. Strength and rheology tests (yield stress and viscosity) as well as microstructure analysis using SEM, XRD, and TG/DTG were conducted to compare its performance with ordinary Portland cement type I (PCI) and PCI-slag blended binder.

The proposed slag binder consists of 91\% GGBFS, 3\% clinker, $5 \%$ desulfurized gypsum, and $1 \%$ mirabilite, and it has a lower cost and is more environmentally friendly than cement. The backfill slurry with PCI binder had a higher early strength due to the fast hydration rate of clinker, while the developed slag binder has better mechanical performance after midterm (7 d) and long-term ( $28 \mathrm{~d}$ ) curing, which is beneficial for practical mining applications.

The rheological properties showed that adding slag to HDB produced a higher yield stress, while changing the binder type did not significantly change the viscosity; however, a more practical parameter-the pressure drop calculated from the Buckingham-Reiner friction factor correlation-showed that SB-HDB was not significantly different than PCI, which indicates that $\mathrm{SB}$ is suitable for mine backfilling.

The validation tests showed that the proposed SB can provide a sustainable binder choice for the mining industry with better performance and a lower cost.

\section{Data Availability}

The raw and processed data required to reproduce these findings are available to download from [https://doi.org/10. 17632/7hrw5bgwj3.3].

\section{Conflicts of Interest}

The authors declare that they have no conflicts of interest.

\section{Authors' Contributions}

B. X. and X. Y. conceptualized the study; B. X. was involved in the methodology; X. Y. was responsible for the software; B. X. and X. Y. validated the study; B. X. performed the formal analysis, X. Y. investigated the study; X. Y. collected the resources; B. X. curated the data; B. X. wrote, prepared, reviewed, and edited the original draft and visualized the study; Q. G. supervised the study and was involved in the project administration and funding acquisition.

\section{Acknowledgments}

The authors are grateful for the help of Longshou Mine, Jinchuan Group Co., Ltd. for providing the aggregate, PCI, and blast furnace slag. This study was funded by the National Key Research and Development Program of China (grant no. 2017YFC0602903).

\section{References}

[1] W. Matthes, A. Vollpracht, Y. Villagrán et al., "Ground granulated blast-furnace slag," "Ground granulated blastfurnace slag," in RILEM State-of-the-Art Reports, N. De Belie, M. Soutsos, and E. Gruyaert, Eds., pp. 1-53, Springer International Publishing, Berlin, Germany, 2018.

[2] M. L. Berndt, "Properties of sustainable concrete containing fly ash, slag and recycled concrete aggregate," Construction and Building Materials, vol. 23, no. 7, pp. 2606-2613, 2009.

[3] M. K. Dash, S. K. Patro, and A. K. Rath, "Sustainable use of industrial-waste as partial replacement of fine aggregate for preparation of concrete-a review," International Journal of Sustainable Built Environment, vol. 5, no. 2, pp. 484-516, 2016.

[4] P. Ahmedzade and B. Sengoz, "Evaluation of steel slag coarse aggregate in hot mix asphalt concrete," Journal of Hazardous Materials, vol. 165, no. 1-3, pp. 300-305, 2009.

[5] E. Vejmelková, M. Keppert, S. Grzeszczyk, B. Skaliński, and R. Černý, "Properties of self-compacting concrete mixtures containing metakaolin and blast furnace slag," Construction and Building Materials, vol. 25, no. 3, pp. 1325-1331, 2011.

[6] A. Kavak and G. Bilgen, "Reuse of ground granulated blast furnace slag (GGBFS) in lime stabilized embankment 
materials," International Journal of Engineering and Technology, vol. 8, no. 1, pp. 11-14, 2016.

[7] E. Crossin, "The greenhouse gas implications of using ground granulated blast furnace slag as a cement substitute," Journal of Cleaner Production, vol. 95, pp. 101-108, 2015.

[8] C. Li, H. Sun, and L. Li, "A review: the comparison between alkali-activated slag $(\mathrm{Si}+\mathrm{Ca})$ and metakaolin $(\mathrm{Si}+\mathrm{Al})$ cements," Cement and Concrete Research, vol. 40, no. 9, pp. 1341-1349, 2010.

[9] C. Hackländer-Woywadt, "Grinding of granulated blastfurnace slag in Loesche vertical roller mills," "Grinding of granulated blastfurnace slag in Loesche vertical roller mills," in Proceedings of the 5th European Slag Conference: Proceedings Slag Products-Providing Sustainable Solutions for the Built Environment, H. Motz and P. Verhaag, Eds., EUROSLAG Publication, Luxembourg, pp. 181-192, September 2007.

[10] A. Ehrenberg, " $\mathrm{CO}_{2}$ emissions and energy consumption of granulated blastfurnace slag," $\mathrm{CO}_{2}$ emissions and energy consumption of granulated blastfurnace slag," in Proceedings of the 3rd European Slag Conference: Proceedings Manufacturing and Processing of Iron and Steel Slags, J. Geiseler and M. Dean, Eds., EUROSLAG Publication, Keyworth, UK, pp. 151-166, October 2002.

[11] S.-D. Wang and K. L. Scrivener, "Hydration products of alkali activated slag cement," Cement and Concrete Research, vol. 25, no. 3, pp. 561-571, 1995.

[12] I. Ismail, S. A. Bernal, J. L. Provis, S. Hamdan, and J. S. J. Van Deventer, "Drying-induced changes in the structure of alkali-activated pastes," Journal of Materials Science, vol. 48, no. 9, pp. 3566-3577, 2013.

[13] Y. Ding, J.-G. Dai, and C.-J. Shi, "Mechanical properties of alkali-activated concrete: a state-of-the-art review," Construction and Building Materials, vol. 127, pp. 68-79, 2016.

[14] P. H. R. Borges, N. Banthia, H. A. Alcamand, W. L. Vasconcelos, and E. H. M. Nunes, "Performance of blended metakaolin/blastfurnace slag alkali-activated mortars," Cement and Concrete Composites, vol. 71, pp. 42-52, 2016.

[15] R. Rankine, M. Pacheco, and N. Sivakugan, "Underground mining with backfills," Soils and Rocks, vol. 30, pp. 93-101, 2007.

[16] K. Klein and D. Simon, "Effect of specimen composition on the strength development in cemented paste backfill," $\mathrm{Ca}$ nadian Geotechnical Journal, vol. 43, no. 3, pp. 310-324, 2006.

[17] A. Gandhe, P. S. Upadhyaya, and C. Lee, "Paste backfill-AIMS towards sustainable underground mining," Journal of Mines, Metals and Fuels, vol. 61, pp. 219-224, 2013.

[18] L. Yang, J. Qiu, H. Jiang, S. Hu, H. Li, and S. Li, "Use of cemented super-fine unclassified tailings backfill for control of subsidence," Minerals, vol. 7, no. 11, p. 216, 2017.

[19] G. A. Habeeb and M. M. Fayyadh, "Rice husk ash concrete: the effect of RHA average particle size on mechanical properties and drying shrinkage," Australian Journal of Basic and Applied Sciences, vol. 3, pp. 1616-1622, 2009.

[20] T. Ikeda, M. Boero, and K. Terakura, "Hydration properties of magnesium and calcium ions from constrained first principles molecular dynamics," Journal of Chemical Physics, vol. 127, Article ID 074503, 2007.

[21] O. Peyronnard and M. Benzaazoua, "Alternative by-product based binders for cemented mine backfill: recipes optimisation using Taguchi method," Minerals Engineering, vol. 29, pp. 28-38, 2012.
[22] H. Jiang, Z. Qi, E. Yilmaz, J. Han, J. Qiu, and C. Dong, "Effectiveness of alkali-activated slag as alternative binder on workability and early age compressive strength of cemented paste backfills," Construction and Building Materials, vol. 218, pp. 689-700, 2019.

[23] F. Puertas, S. Martínez-Ramírez, S. Alonso, and T. Vázquez, "Alkali-activated fly ash/slag cements," Cement and Concrete Research, vol. 30, no. 10, pp. 1625-1632, 2000.

[24] M. Michel, J.-F. Georgin, J. Ambroise, and J. Péra, “The influence of gypsum ratio on the mechanical performance of slag cement accelerated by calcium sulfoaluminate cement," Construction and Building Materials, vol. 25, no. 3, pp. 1298-1304, 2011.

[25] G. Sarkar and S. Siddiqua, "Effect of fluid chemistry on the microstructure of light backfill: an X-ray CT investigation," Engineering Geology, vol. 202, pp. 153-162, 2016.

[26] K. L. Scrivener, P. Juilland, and P. J. M. Monteiro, "Advances in understanding hydration of Portland cement," Cement and Concrete Research, vol. 78, pp. 38-56, 2015.

[27] O. R. Ogirigbo and L. Black, "Influence of slag composition and temperature on the hydration and microstructure of slag blended cements," Construction and Building Materials, vol. 126, pp. 496-507, 2016.

[28] A. Gruskovnjak, B. Lothenbach, F. Winnefeld et al., "Hydration mechanisms of super sulphated slag cement," Cement and Concrete Research, vol. 38, no. 7, pp. 983-992, 2008.

[29] Y. Anderberg, "Spalling phenomena of HPC and OC," in Proceedings of the International Workshop on Fire Performance of High-Strength Concrete, NIST, Gaithersburg, MD, USA, pp. 69-73, Feburary 1997.

[30] I. Pane and W. Hansen, "Investigation of blended cement hydration by isothermal calorimetry and thermal analysis," Cement and Concrete Research, vol. 35, no. 6, pp. 1155-1164, 2005.

[31] M. Fall and M. Pokharel, "Coupled effects of sulphate and temperature on the strength development of cemented tailings backfills: Portland cement-paste backfill," Cement and Concrete Composites, vol. 32, no. 10, pp. 819-828, 2010.

[32] L. Chaurasia, V. Bisht, L. P. Singh, and S. Gupta, "A novel approach of biomineralization for improving micro and macro-properties of concrete," Construction and Building Materials, vol. 195, pp. 340-351, 2019.

[33] W. Liu, S. Yan, Y. An, and H. Li, "Research on special cement for the concrete with ultra-fine iron tailings," Advanced Materials Research, vol. 476-478, pp. 1974-1978, 2012.

[34] G. Xue, E. Yilmaz, W. Song, and S. Cao, "Compressive strength characteristics of cemented tailings backfill with alkali-activated slag," Applied Sciences, vol. 8, no. 9, p. 1537, 2018.

[35] Y. Zhou, H. Deng, and J. Liu, "Rational utilization of fine unclassified tailings and activated blast furnace slag with high calcium," Minerals, vol. 7, no. 4, p. 48, 2017.

[36] M. Torres-Carrasco, C. Rodríguez-Puertas, M. d. M. Alonso, and F. Puertas, "Alkali activated slag cements using waste glass as alternative activators. rheological behaviour," Boletín de la Sociedad Española de Cerámica y Vidrio, vol. 54, no. 2, pp. 45-57, 2015.

[37] M. Palacios, P. F. G. Banfill, and F. Puertas, "Rheology and setting of alkali-activated slag pastes and mortars: effect if organic admixture," ACI Materials Journal, vol. 105, pp. $140-148,2008$.

[38] N. Jia, M. Gourma, and C. P. Thompson, "Non-Newtonian multi-phase flows: on drag reduction, pressure drop and 
liquid wall friction factor," Chemical Engineering Science, vol. 66, no. 20, pp. 4742-4756, 2011.

[39] B. Bharathan, M. McGuinness, S. Kuhar, M. Kermani, F. P. Hassani, and A. P. Sasmito, "Pressure loss and friction factor in non-Newtonian mine paste backfill: modelling, loop test and mine field data," Powder Technology, vol. 344, pp. 443-453, 2019. 